\title{
Accumulative Roll Bonding of Pure Copper and IF Steel
}

\author{
Saeed Tamimi, ${ }^{1,2}$ Mostafa Ketabchi, ${ }^{1}$ Nader Parvin, ${ }^{1}$ Mehdi Sanjari, ${ }^{3}$ and Augusto Lopes ${ }^{4}$ \\ ${ }^{1}$ Mining and Metallurgical Engineering Department, Amirkabir University of Technology, Tehran 15875-4413, Iran \\ ${ }^{2}$ Department of Mechanical Engineering, TEMA, University of Aveiro, 3810-193 Aveiro, Portugal \\ ${ }^{3}$ Mining and Materials Engineering Department, McGill University, Montreal, QC, Canada H3A OE8 \\ ${ }^{4}$ Departamento de Engenharia de Materiais e Ceramica, CICECO, University of Aveiro, 3810-193 Aveiro, Portugal
}

Correspondence should be addressed to Saeed Tamimi; saeed.tamimi@gmail.com

Received 13 June 2014; Revised 20 August 2014; Accepted 24 August 2014; Published 23 September 2014

Academic Editor: Mohammad Reza Toroghinejad

Copyright (C) 2014 Saeed Tamimi et al. This is an open access article distributed under the Creative Commons Attribution License, which permits unrestricted use, distribution, and reproduction in any medium, provided the original work is properly cited.

Severe plastic deformation is a new method to produce ultrafine grain materials with enhanced mechanical properties. The main objective of this work is to investigate whether accumulative roll bonding (ARB) is an effective grain refinement technique for two engineering materials of pure copper and interstitial free (IF) steel strips. Additionally, the influence of severely plastic deformation imposed by ARB on the mechanical properties of these materials with different crystallographic structure is taken into account. For this purpose, a number of ARB processes were performed at elevated temperature on the materials with $50 \%$ of plastic deformation in each rolling pass. Hardness of the samples was measured using microhardness tests. It was found that both the ultimate grain size achieved, and the degree of bonding depend on the number of rolling passes and the total plastic deformation. The rolling process was stopped in the 4th cycle for copper and the 10th cycle for IF steel, until cracking of the edges became pronounced. The effects of process temperature and wire-brushing as significant parameters in ARB process on the mechanical behaviour of the samples were evaluated.

\section{Introduction}

Recently, much attention has been directed to ultragrain refining of metallic materials, where the grain size is reduced to less than one micrometre. According to Hall-Petch relationship, it is expected that ultrafine grain (UFG) structure would result in higher strength $[1,2]$. Producing high strength materials, particularly without alloying, is very important in economical point of view. Severe plastic deformation (SPD) techniques have been known in the last decades as effective methods to produce UFG materials.

The efficiency of traditional SPD techniques has been carried out such as equal channel angular pressing (ECAP) and high-pressure torsion (HPT) for grain refinement of a number of metallic materials, for example, $[3,4]$. It has been shown that the UFG microstructure can be achieved using these methods; however, the typical sizes of the samples deformed by ECAP and HPT are small [5]. Furthermore, these types of SPD processes require special and/or expensive equipment. In recent years, a number of alternative SPD technologies have been developed, including equal channel angular rolling, cyclic bending, and accumulative roll bonding (ARB) in which the mentioned limitations were partially omitted $[5,6]$. These SPD processes have potential to be adopted by the industry to produce UFG materials in the form of large sheets, due to their possibility as continuous processes. Saito et al. developed the ARB process for the first time in which SPD strategies are applied in a simple rolling process $[7,8]$. This SPD process has then been used to fabricate UFG microstructures in various engineering materials and the effect of UFG structure on their mechanical properties have been studied, for example, [9-12]. However, there is a lack of study on the comparison of efficacy of ARB on the microstructure and its induced mechanical response of two different crystallographic structure materials. This study focuses on the ARB process in IF steel and pure copper sheets. The process parameters such as plastic deformation, processing temperature, and sample preparation factor are 


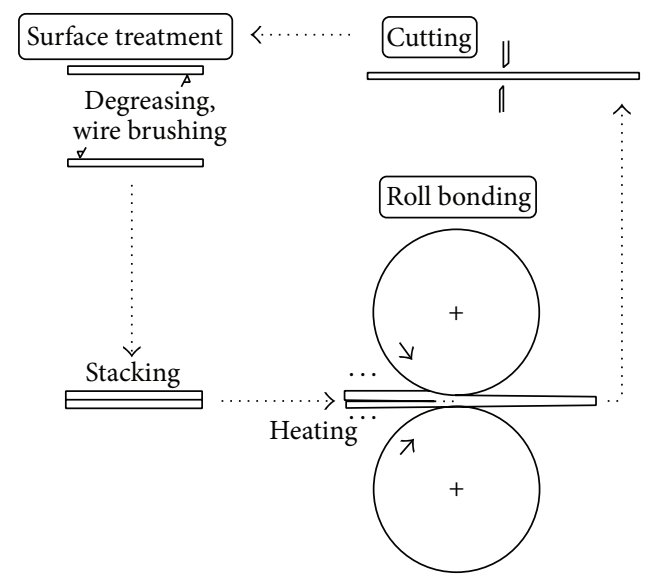

FIGURE 1: A schematic illustration of ARB process [9].

taken into consideration. The work deals with mechanical properties and microstructure observations after ARB process to investigate the influence of the process temperature and wire-brushing on the materials' properties.

\section{Technical Work Preparation}

2.1. Materials and Samples Preparation. The chemical analyses of pure copper and IF steel are given in Table 1 in which their initial mean grain sizes are 37 and 18 micrometre, respectively.

A schematic illustration of ARB technique is represented in Figure 1. The process is conducted under the conditions that the reduction in thickness per cycle is $50 \%$ (equivalent strain of 0.8) [8]. In order to remove the oxide layers and scale on the surface and also to increase the bonding capability, the surfaces of the strips were roughened using a metallic wire brush. After brushing, the surfaces were cleaned using acetone. The strips were then joined on the roughened surfaces by a couple of rivets. Rolling at elevated temperature is advantageous for join-ability and workability, though very high temperature would cause recrystallization and omit the accumulated strain effects. Therefore, the samples were placed in the furnace and preheated to a particular temperature for each case. Subsequently, the preheated samples were ARB-processed at a circumferential velocity of $0.47 \mathrm{~m} / \mathrm{s}$. No-lubrication condition was applied during the rolling passes. The principle of the ARB process has been reported previously, for example, [13].

The preheating condition in each pass was holding in the furnace at $550^{\circ} \mathrm{C}$ and $400^{\circ} \mathrm{C}$ for $300 \mathrm{~s}$ for IF steel and pure copper sheets, respectively. It can be considered a $50^{\circ} \mathrm{C}$ for thermal losing after taking the samples out of furnace as well as rolling process for both cases. Ten ARB cycles were carried out for IF steel sample. However, due to the earlier pronounced cracks in the edges of the sheet of copper after four passes, the process was stopped after the forth cycle.

2.2. Materials Characterization. Bonding between different metallic layers after fracture was studied by scanning electron microscopy (SEM) using back scatter electron probe. The microstructure of samples was investigated by an optical microscopy and scanning electron microscopy (SEM) using secondary electron probe for samples. The microstructures were observed on the planes perpendicular to the transverse direction (TD). The etch solution was natal for IF steel, and pure copper samples were etched by $50 \mathrm{~mL} \mathrm{HCl,} 5 \mathrm{gr} \mathrm{FeCl}_{3}$, $100 \mathrm{~mL} \mathrm{H}_{2} \mathrm{O}$ after mechanical polishing. Furthermore, an electron backscattering diffraction (EBSD) was used to study the effect of ARB on the dislocation organization as well as the misorientation in various directions in the rolling plane. The mean value of hardness in each sample was measured using a Vickers microhardness with the load of $15 \mathrm{gr}$ load for the copper and $50 \mathrm{gr}$ for the IF steel samples. Additionally, the influence of process temperature was investigated on the mechanical properties of samples. To this end, the metallic sheets were processed up to four ARB cycles in various temperatures. The copper sheets were taking place in the furnace in the temperature range of $250-400^{\circ} \mathrm{C}$ for one hour, and the range of $400-550^{\circ} \mathrm{C}$ for one hour was also considered for preheating of IF steel before ARB process. Mean values of hardness of these specimens were measured. Finally, the effect of metallic wire-brushing on surface of the samples, as a preparation step, was observed. For this goal, two pieces of strip, a wire-brushed and a not-wire-brushed sheets, were joined with rivets and then followed by ARB process. The variation of mean value of hardness at each area throughout the sheet thickness was measured.

\section{Results and Discussion}

\subsection{Interfaces and Microstructure}

3.1.1. Interfaces. The ARB process was successfully performed up to ten cycles without any shape defects in IF specimens and 4 cycles for copper samples. SEM macrographs of ARBprocessed IF steel after fracture for different numbers of ARB passes are shown in Figure 2. The number of interfaces for each ARB pass is

$$
N=2^{n}-1,
$$

where $n$ is the number of passes and $N$ indicates the number of interfaces across the sheet thickness. In case of the specimen of ten cycles, 1023 interfaces exist across the thickness (Figure 2(c)). Figure 2 shows that unbonded regions were decreased in a higher number of ARB passes. In other words, the subsequent rolling improves the quality of bonds between the surfaces introduced in the previous cycles. A similar observation has also been reported by Saito et al. [8].

3.1.2. Microstructure Evolution. Figures 3 and 4 illustrate the optical microstructures observed on the TD plane of the specimens. Microstructural evolution of pure copper through ARB in Figure 3 shows that by increasing the number of cycles, grain shapes become more elongated and finer. Mean grain thickness grew a little in cycle four in comparison to previous cycles. The interface can be clearly seen in 
TABLE 1: Chemical analysis of IF steel and pure copper.

\begin{tabular}{lcccccccccccccccccccc}
\hline & $\mathrm{C}$ & $\mathrm{Mn}$ & $\mathrm{Mg}$ & $\mathrm{Cr}$ & $\mathrm{Ti}$ & $\mathrm{Ni}$ & $\mathrm{V}$ & $\mathrm{Mo}$ & $\mathrm{Ta}$ & $\mathrm{Co}$ & $\mathrm{N}$ & $\mathrm{Nb}$ & $\mathrm{P}$ & $\mathrm{Pb}$ & $\mathrm{Zn}$ & $\mathrm{Fe}$ & $\mathrm{Cu}$ & $\mathrm{Al}$ \\
\hline IF steel & 0.004 & 0.06 & - & 0.015 & 0.040 & 0.017 & 0.001 & 0.002 & 0.002 & 0.002 & Trace & Trace & - & - & - & Remained & - & - \\
Pure copper & - & 0.003 & - & 0.002 & - & 0.03 & - & - & - & 0.02 & - & - & 0.001 & 0.002 & 0.05 & 0.07 & 99.74 & 0.02 \\
\hline
\end{tabular}

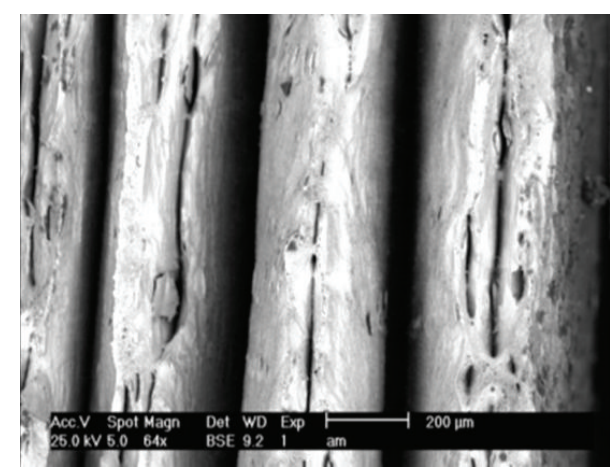

(a)

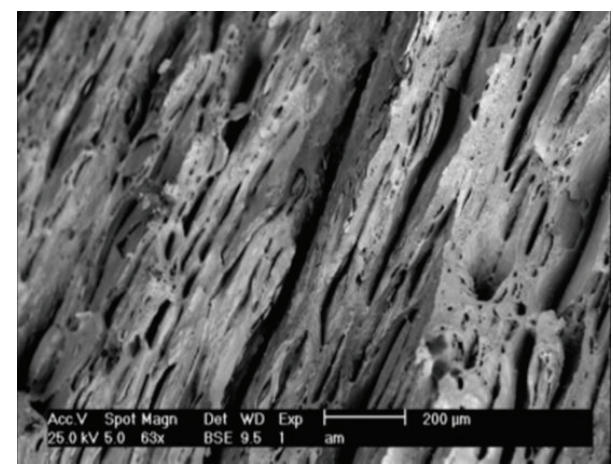

(b)

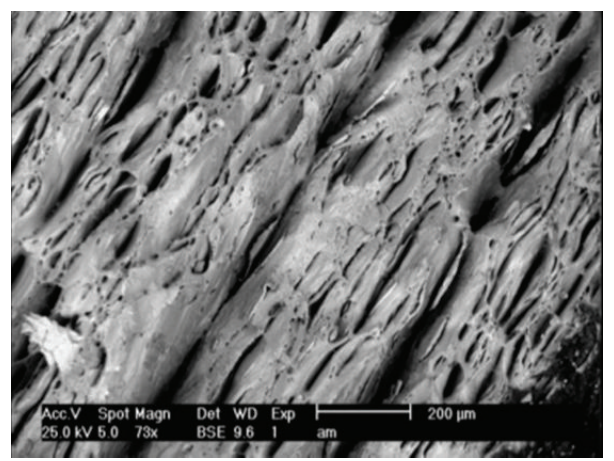

(c)

FIGURE 2: Interfaces of IF samples after (a) 4, (b) 8, and (c) 10 cycles ARB, preheating of $550^{\circ} \mathrm{C}$.

Figure 3(d). Additionally, Figure 4 shows the microstructure of annealed (as received sample) IF steel as well as the samples produced by one and three ARB cycles. The microstructure of the specimen of one ARB-processed cycle showed relatively large grains and elongated to the rolling direction with clear grain boundaries. As the number of ARB cycles increases, the microstructures become finer and more complicated. After 3 cycles it is difficult to detect any grains and their boundaries by optical microscopy.

Figure 5 presents the SEM micrographs of the copper sheets after ARB process. The grains become finer and more complicated by number of cycles. The microstructure grew very slightly at the last pass of ARB.

Additionally, SEM micrographs of the ARB-processed IF steel after different amounts of strain are shown in Figure 6. New ultrafine grains can be seen in the specimens. The fraction of these ultrafine grains increased with the number of ARB cycles. In Figure 6(c) the specimen after six cycles was covered with small grains with less than $500 \mathrm{~nm}$ thickness, surrounded by clear boundaries. With increasing the number of $\mathrm{ARB}$ cycles, the mean grain size reduces and reaches to a minimum value at 8 th pass. The grain size of IF steel increases slightly in pass 9 and 10 of ARB.

Figure 7 presents an EBSD analysis of the IF steel sample deformed by the 7th pass of ARB. The ultrafine grains can be seen in this figure. The grain size distribution of this sample indicates that seven passes of ARB process could successfully decrease the grain size down to one micrometre.

3.1.3. Discussion. Microstructure evolution during ARB has been investigated for different engineering materials in which the formation of UFG with the number of ARB cycles is similar (e.g., [14-16]). Generally, with increasing the extent of plastic deformation, the generated dislocations move to the direction of the applied load with subsequent interlocking to the neighbouring dislocations. Dislocation tangles are then formed which contain regions with high dislocation density. The mechanism of grain refining in ARB process has been suggested by Tsuji et al. [17] using geometrical necessary $(\mathrm{g}-\mathrm{n})$ dislocations. It has been suggested that the continuous changes in misorientation are converted into the planer boundaries by rearrangement of the g-n dislocations. 


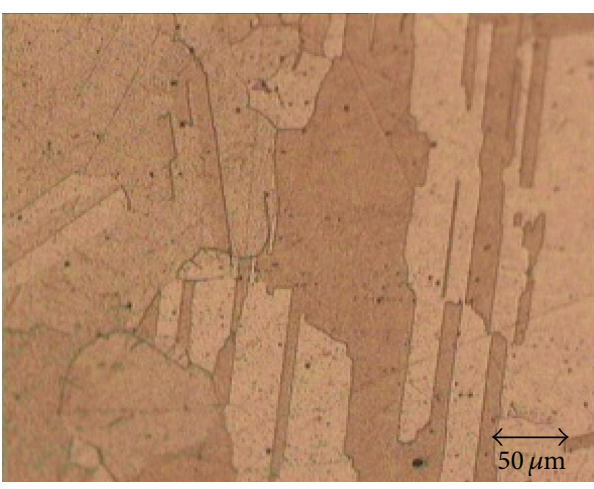

(a)

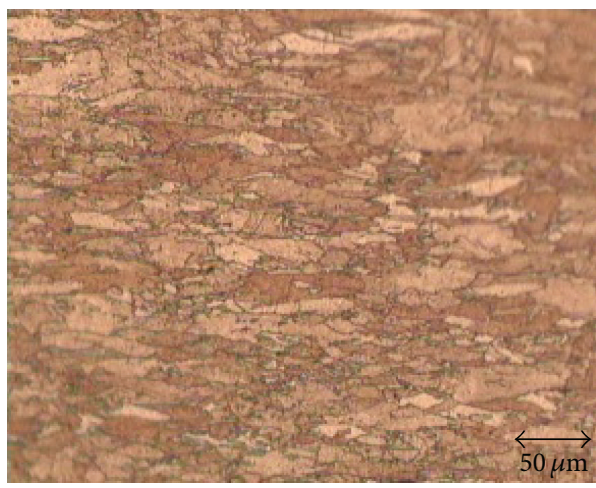

(c)

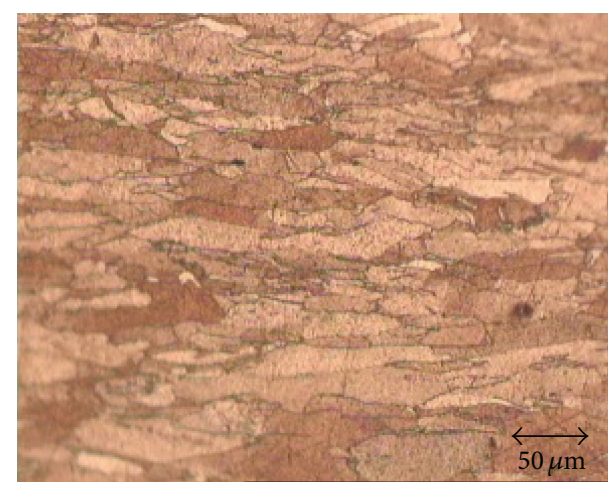

(b)

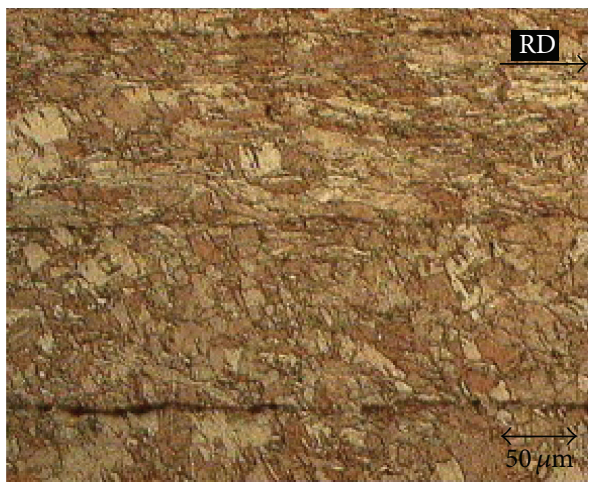

(d)

FIGURE 3: Optical images of TD plane in pure copper samples, (a) annealed, (b) two, (c) three, and (d) four ARB cycles, preheated at $400^{\circ} \mathrm{C}$.

There exist two types of boundaries in a sample processed by ARB: the extended lamellar boundaries parallel to the rolling plane and the short transverse boundaries interconnecting the lamellar boundaries. Figure 8 shows the misorientation profiles along two directions of TD and RD of the 7th ARBprocessed IF steel which are indicated in Figure 7, with line $\mathrm{A}-\mathrm{A}$ and line $\mathrm{B}-\mathrm{B}$, respectively. The misorientation profiles indicate that boundaries parallel to the $\mathrm{RD}$ possess higher misorientation (high angle boundaries) in comparison to those boundaries which are perpendicular to the RD (low angle boundaries). This is in agreement with the work of Huang et al. [18]. A comparison between the EBSD result and the SEM results of the samples with roughly equal strain (Figures 6(c) and 7) shows that SEM analysis can only detect the lamellar boundaries (i.e., high angle boundaries).

The results above indicate that the rate of grain refinement decreases at higher cycles. It should be noted that maximum grain refinement rate is related to the first cycle and then the rate decreases at higher amount of plastic deformation. This observation can be explained by saturation phenomenon where the formation of new dislocation in the deformed grains is difficult $[19,20]$. The results show slightly grain growth in high cycles for both materials (see Figures 5 and 6). The larger amount of energy accumulated in the material as a consequence of the higher reduction in thickness per pass might constitute a driving force for grain growth. Preheating the sample before each ARB pass, as well as the heat generated during the plastic deformation, may accelerate this phenomenon. The results indicate that the pure copper experiences the coarsening after the first pass of ARB whereas IF steel sample shows around the 8th pass of ARB process. This shows that the pure copper is more sensitive to amount of accumulated strain compared to the IF steel sample for microstructure growing. That might be attributed to easy motion of dislocations resulted from its relatively higher stacking fault energy of pure copper. In case of pure copper, therefore, boundaries are gradually diminished and grains become larger after the first ARB pass and in case of IF steel coarsening occurs after the 8th ARB pass.

3.2. Mechanical Properties. Figure 9 illustrates the changes in Vickers microhardness with ARB cycles. In IF samples the hardness increased rapidly at initial stage. After 7 cycles, the rate of increasing hardness reduces. Maximum hardness was reported after 8 cycles being $247 \mathrm{HV}$, at which the trend is reversed. The copper samples present a similar trend. The hardness increased considerably during after first cycle and decreased after second rolling pass.

3.2.1. Temperature Effects. The temperature of the process and the accumulated strain determines the amount of recrystallization. The influence of process temperature on the material properties was observed systematically by measuring 


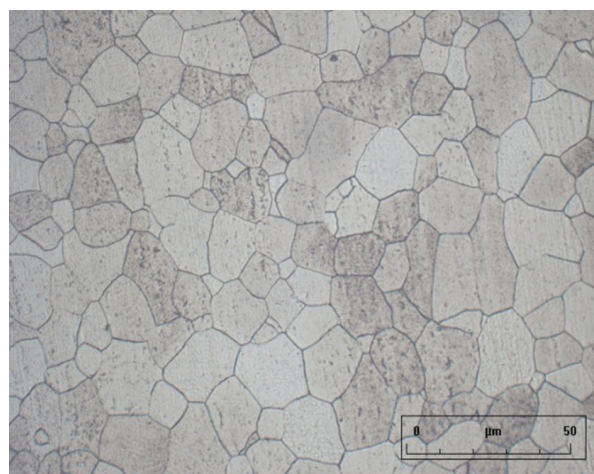

(a)

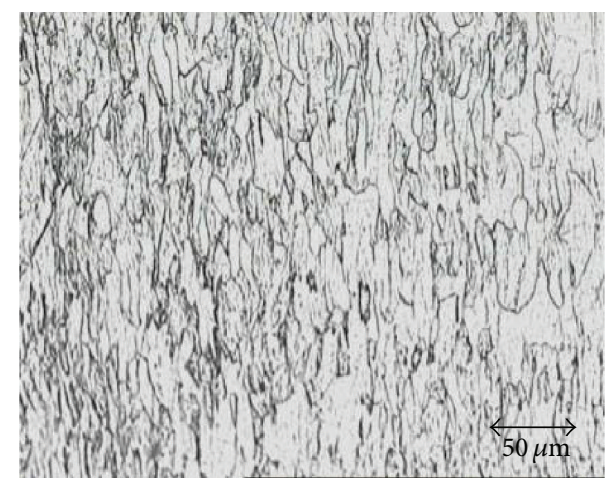

(b)

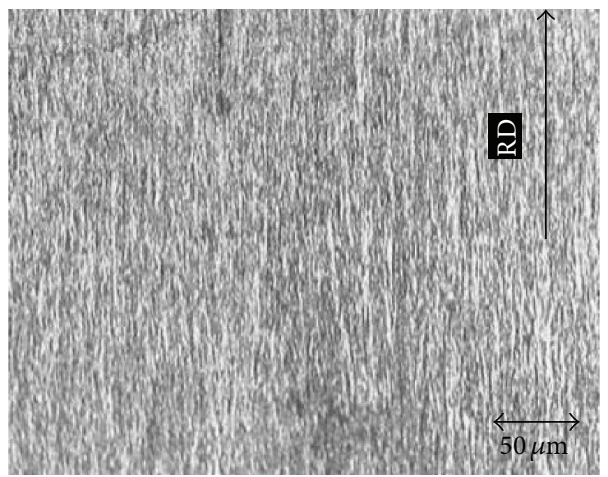

(c)

FIGURE 4: Optical images of TD plane in IF steel samples, (a) annealed, (b) after one cycle, and (c) after three ARB cycles, preheated at $550^{\circ} \mathrm{C}$.

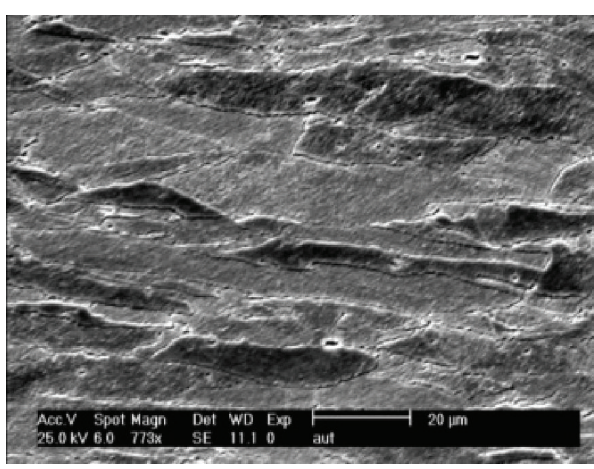

(a)

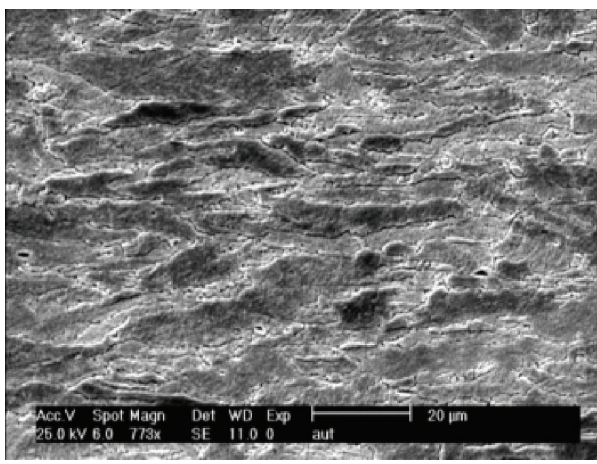

(c)

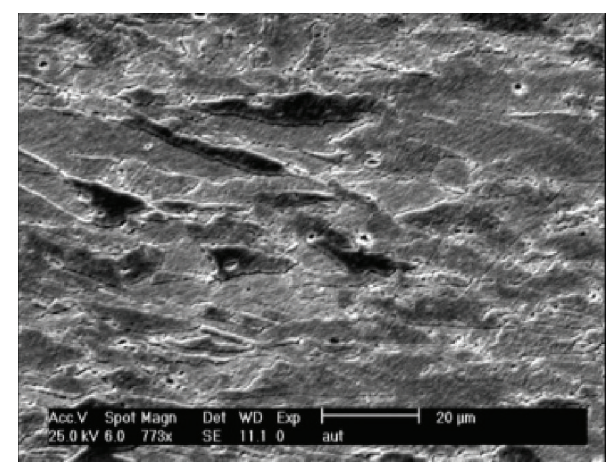

(b)

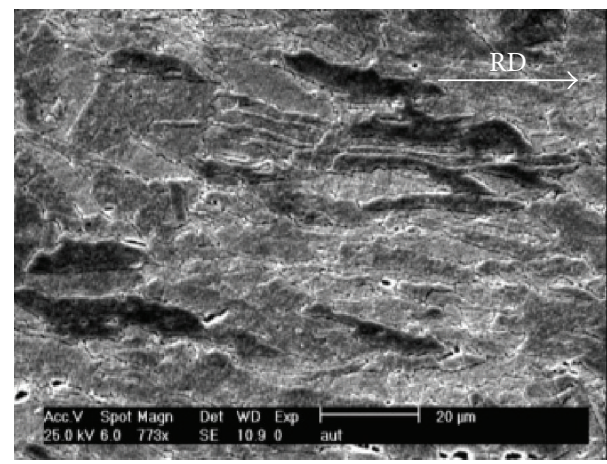

(d)

FIGURE 5: SEM micrographs in TD plane of pure copper, (a) one, (b) two, (c) three, and (d) four passes of $\mathrm{ARB}$, preheated at $400^{\circ} \mathrm{C}$. 


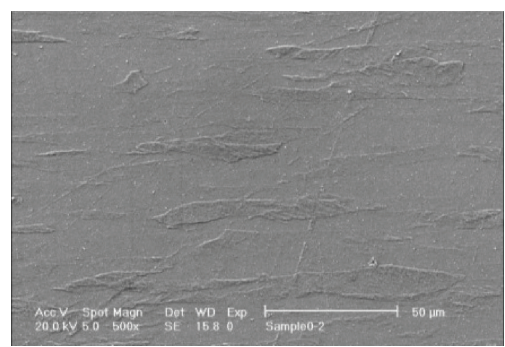

(a)

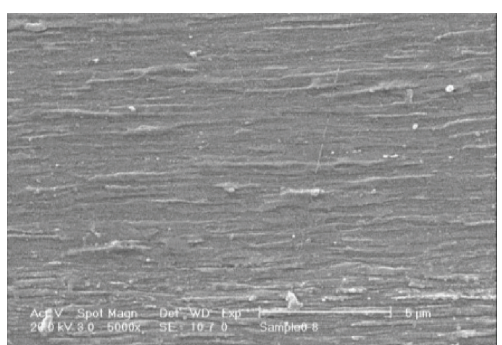

(d)

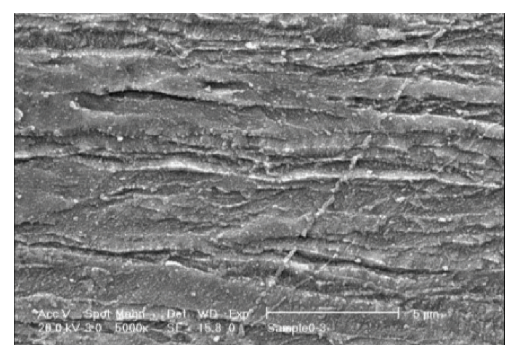

(b)

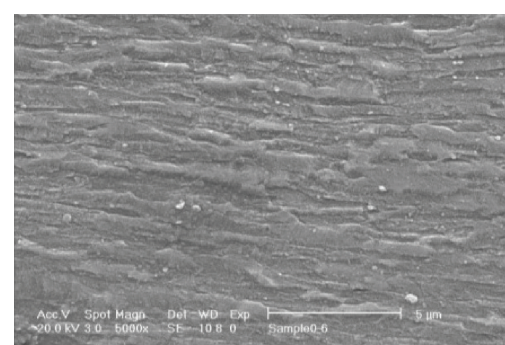

(c)

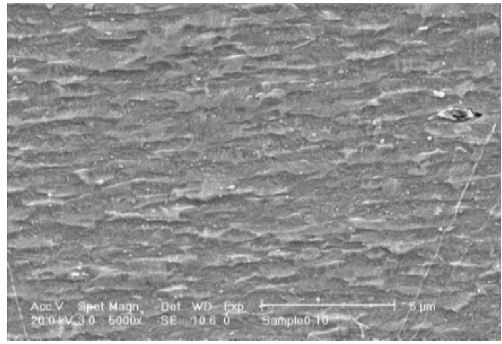

(e)

FIgURE 6: SEM micrographs in TD plane of IF steel, (a) one, (b) three, (c) six, (d) eight, and (e) ten ARB cycles; preheated at $550^{\circ} \mathrm{C}$.
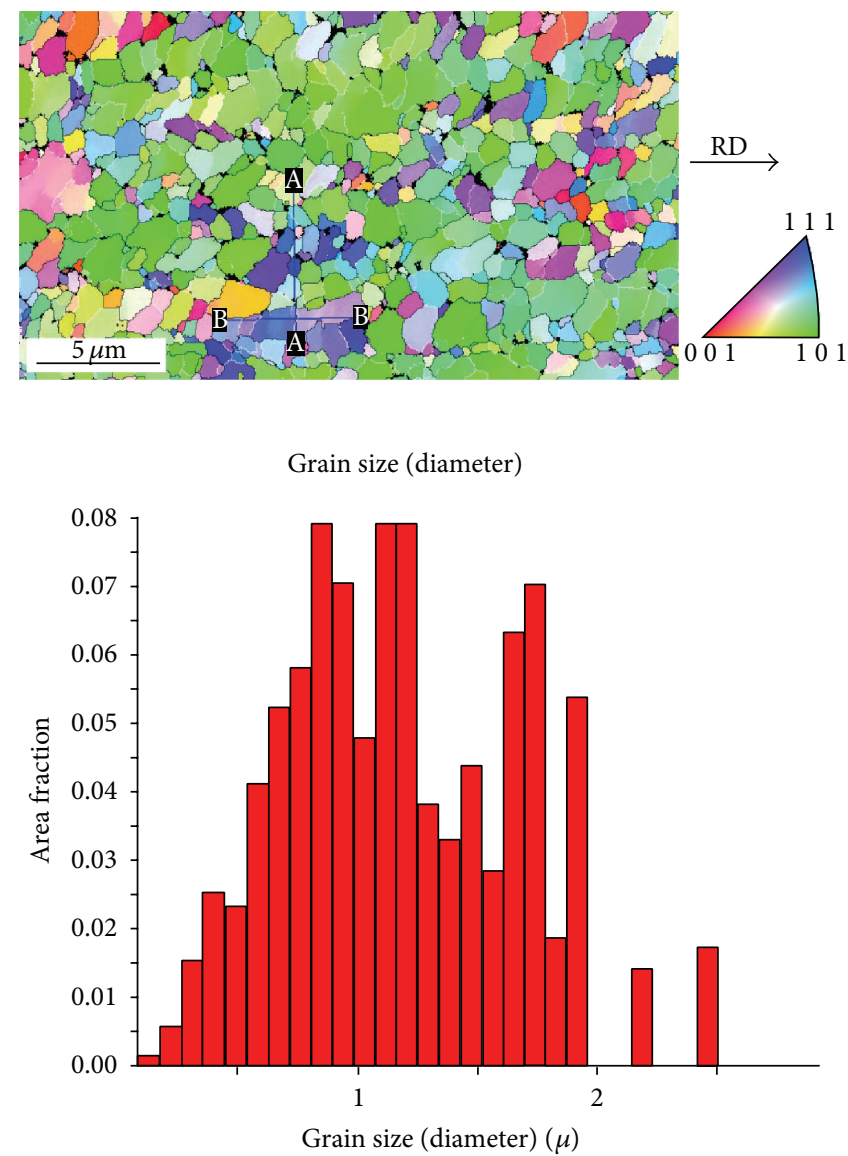

FIGURE 7: EBSD image and grain size distribution of IF steel from rolling plane after the 7th pass of ARB; preheated at $550^{\circ} \mathrm{C}$. 


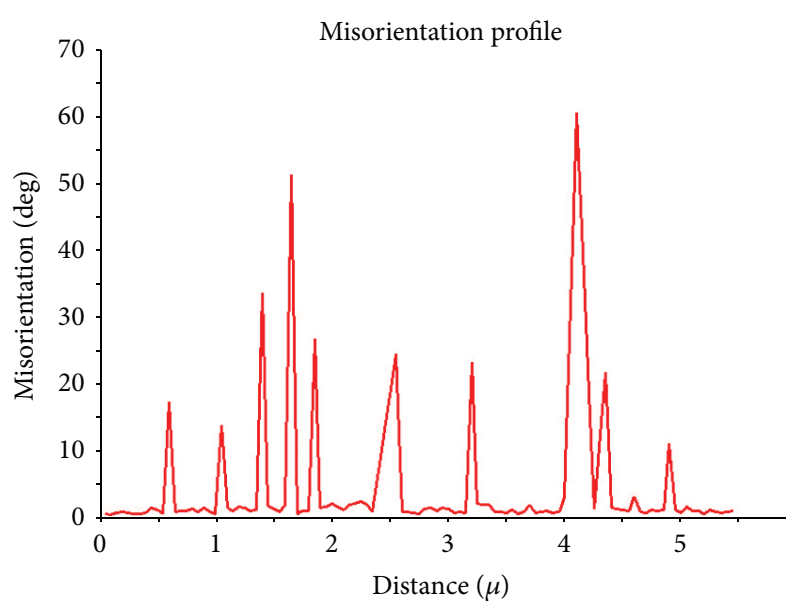

(a)

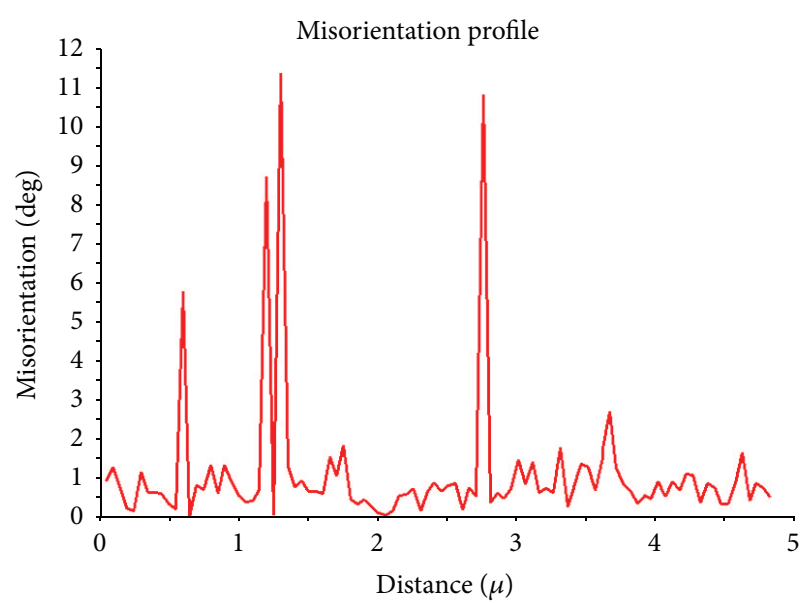

(b)

FIGURE 8: Misorientation profile along (a) transvers (line A-A) and (b) rolling (line B-B) directions in Figure 7.

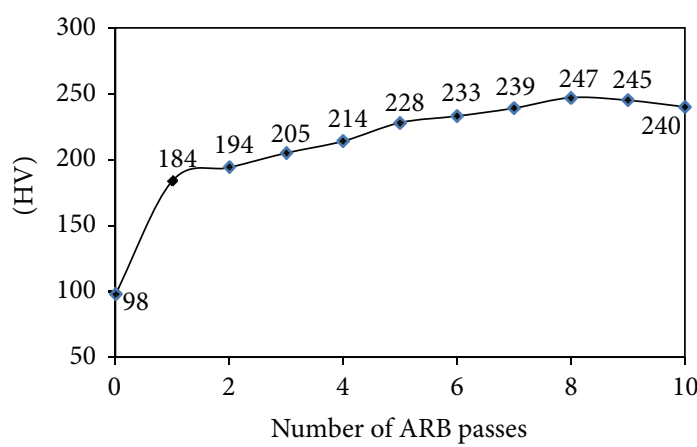

(a)

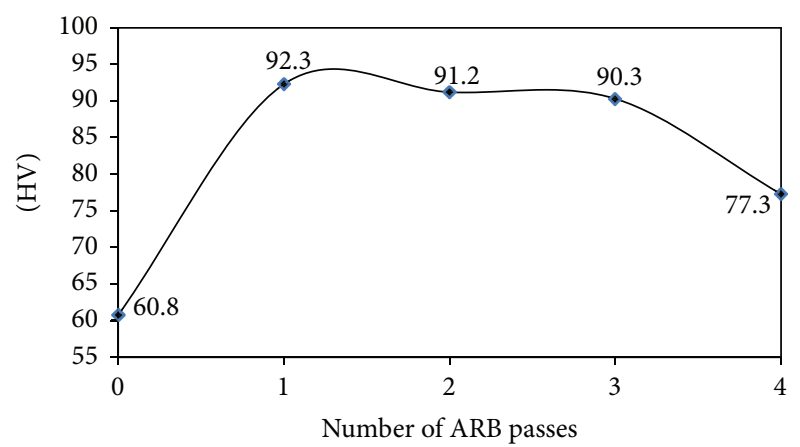

(b)

FIGURE 9: Variation of microhardness after various ARB cycles: (a) IF steel preheated at $550^{\circ} \mathrm{C}$ and (b) pure copper preheated at $400^{\circ} \mathrm{C}$.

the hardness evolution for different preheating conditions. Figure 10 shows the effect of temperature during rolling on hardness in IF steel and pure copper samples. Both materials were processed up to four ARB cycles in various temperatures. According to the graphs, at higher ARB temperatures, hardness of the samples decreases to lower values.

With the aim of enhanced mechanical properties, the results of Figure 10 suggest lower temperatures for ARB process; however, the quality of the bonding between layers is modified at higher temperatures. Furthermore, since formability of the materials is affected by process temperature, the cracks during the ARB passes have been detected at lower temperatures.

3.2.2. Wire-Brushing Effects. Figure 11 shows the effect of wire-brushing on microhardness across the sheet thickness for both materials. In each case, a single pass of ARB was carried out on two sheets in which only one sheet was wirebrushed. It was found that the difference on hardness of brushed and not-brushed sheets was in about $6 \mathrm{HV}$ for IF steel and $3 \mathrm{HV}$ for pure copper. This difference is attributed with work hardening caused by metallic wire-brushing on the surface regions of the material, although it is too small.

3.2.3. Discussion. Investigations have been conducted to find out whether the dislocation theories could describe the mechanical behaviour of ultrafine grain materials [21, 22]. In general, Hall-Petch relationship may explain that fine grains produced by $A R B$ increase the material hardness. The ultrafine structure achieved by ARB in both materials (Figures 5 and 6) leads to increase in their hardness (Figures 9(a) and 9(b)). In addition, Xing et al. claimed that the plastic deformation produces a large number of dislocations inside the grains. This may make the dislocation movement difficult, leading to increased hardness [23]. By increasing the number of ARB cycles up to final stages, the hardness decreased a little in the observed materials. These phenomena could be due to different reasons. In larger accumulated strains at higher passes during the $\mathrm{ARB}$, the saturation of 


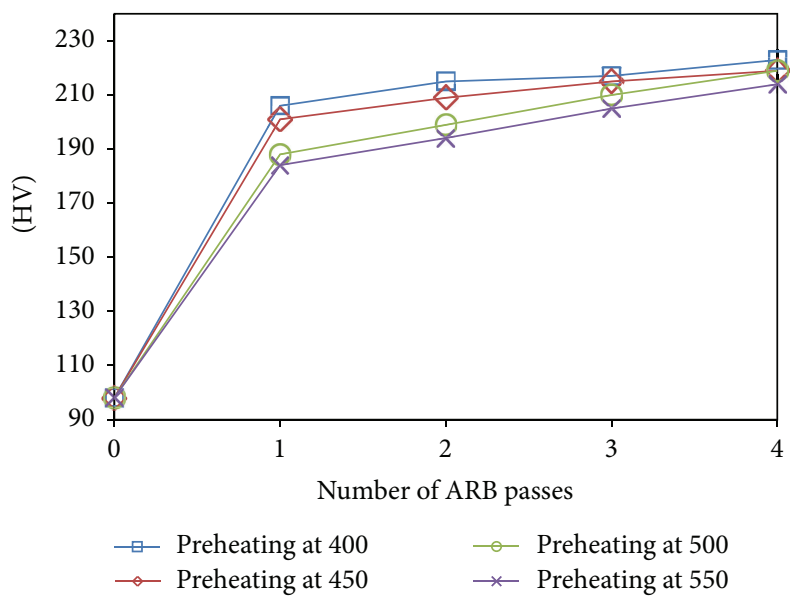

(a)

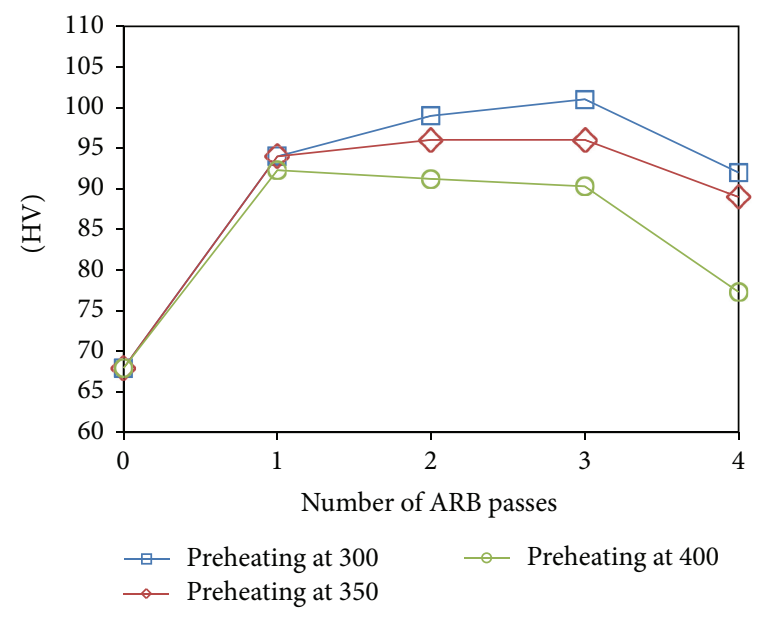

(b)

FIGURE 10: Variation of microhardness with ARB temperature up to four cycles (a) IF steel and (b) pure copper.

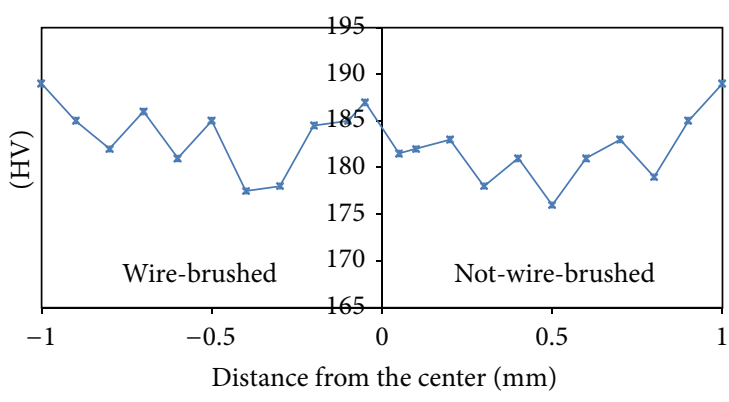

(a)

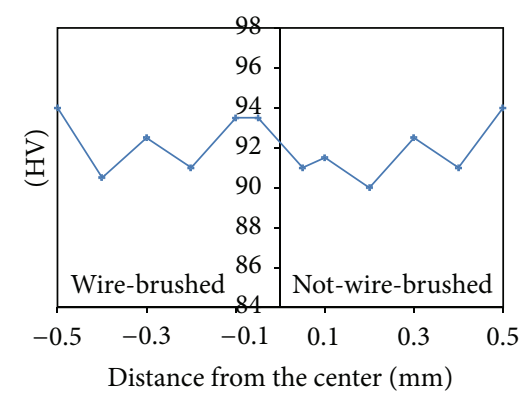

(b)

FIGURE 11: Wire-brushing effect on hardness in first ARB cycle in (a) IF steel (preheated at $550^{\circ} \mathrm{C}$ ) and (b) pure copper (preheated at $400^{\circ} \mathrm{C}$ ).

dislocation may diminish the value of hardness. High value of dislocation density in the grains makes it difficult to produce new dislocations. In this level of plastic deformation, misorientation of the boundaries reaches to the threshold angle of $36^{\circ}$ for boundaries parallel to the rolling direction, reported in previous observations [19, 20, 24]. Moreover, recrystallization, both types of dynamics during the process and static in the furnace (through preheating), may partially occur during the process. In thermodynamic point of view, a higher total plastic strain produced by ARB process results in a premature recrystallization. The mechanisms of the mechanical behaviour seen in Figure 9 (i.e., a dramatic increase of hardness at the beginning and a slight decrease at higher ARB cycles) are similar for both observed materials. However, each material shows this behaviour at certain strains. These particular points are 6.4 and 0.8 as equivalent to plastic strain for IF steel and pure copper, respectively. After the establishment of accumulated strain in both materials, the variation of hardness becomes reverse; that is, the softening occurs. This observation is in agreement with the grain size variations of each material at the certain strain presented in Figures 5 and 6 (i.e., Hall-Petch theory).

It is well known that the temperature of the process has a great impact on the mechanical behaviour of ARB samples, which can be due to dynamic recrystallization through the process as well as static one in the holding time when the sample was placed in the furnace. At higher temperatures the dislocations annihilation leads to reduced number of dislocations. The change in dislocation density varies by stacking fault energy of each material. Figure 10(b) indicates that the maximum hardness variations of copper ARB-processed in lower temperatures reach to maximums in the higher amount of accumulated strains; for instance, the maximum hardness for the case of preheating at $300^{\circ} \mathrm{C}$ was seen after the third ARB pass. This indicates that recrystallization at lower temperature required higher accumulated strain whereas only 0.8 of strain is sufficient for recrystallization at higher temperature $\left(400^{\circ} \mathrm{C}\right)$.

\section{Conclusion}

Present work deals with the influence of severely plastic deformation imposed by ARB process on the properties of two prominent engineering materials: pure copper and IF steel. The results indicate that UFG structures were produced in both materials through ARB. Additionally, the results of hardness test of the samples increase with the number of ARB 
cycles. The high rate of increase of hardness at the beginning passes, followed by decreasing the rate and then saturation, all occur in different amounts of strain in the materials. The IF steel specimen after eight cycles achieved highest hardness of $247 \mathrm{HV}$, which is about 2.5 times the initial value and the pure copper samples after the first cycle achieved highest hardness of $92 \mathrm{HV}$, which is about 1.5 times the initial value. It can be concluded that mean value of hardness distribution along the thickness of the samples was directly proportional to the mean grain size.

Furthermore, the influence of process temperature on the hardness of the samples in different passes of the ARB was studied. The results show that ARB process at lower temperature results in higher hardness in copper and steel sheets; however, it may lead to appear as unbonded area which is undesirable. Additionally, low temperature ARB process causes the quick fracture of the samples at higher strains. Moreover, the presented results indicate that using metallic wire-brushing before each ARB pass causes work hardening on the surface of samples and raises the surface hardness for small values.

\section{Conflict of Interests}

The authors declare that there is no conflict of interests regarding the publication of this paper.

\section{References}

[1] E. O. Hall, "The deformation and ageing of mild steel: III discussion of results," Proceedings of the Physical Society Section $B$, vol. 64, no. 9, pp. 747-752, 1951.

[2] N. L. Petch, "The cleavage strength of polycrystals," The Journal of the Iron and Steel Institute, vol. 174, p. 25, 1953.

[3] V. M. Segal, V. I. Reznikov, A. E. Drobyshevskiy, and V. I. Kopylov, "Plastic working of metals by simple shear," Russian Metallurgy, vol. 1, pp. 99-105, 1981.

[4] Z. Horita, D. J. Smith, M. Furukawa, M. Nemoto, R. Z. Valiev, and T. G. Langdon, "An investigation of grain boundaries in submicrometer-grained Al-Mg solid solution alloys using highresolution electron microscopy," Journal of Materials Research, vol. 11, no. 8, pp. 1880-1890, 1996.

[5] N. Tsuji, Y. Saito, S.-H. Lee, and Y. Minamino, "ARB (accumulative roll-bonding) and other new techniques to produce bulk ultrafine grained materials," Advanced Engineering Materials, vol. 5, no. 5, pp. 338-344, 2003.

[6] H. Utsunomiya, K. Hatsuda, T. Sakai, and Y. Saito, "Continuous grain refinement of aluminum strip by conshearing," Materials Science and Engineering A, vol. 372, no. 1-2, pp. 199-206, 2004.

[7] Y. Saito, N. Tsuji, H. Utsunomiya, T. Sakai, and R. G. Hong, "Ultra-fine grained bulk aluminum produced by accumulative roll-bonding (ARB) process," Scripta Materialia, vol. 39, no. 9, pp. 1221-1227, 1998.

[8] Y. Saito, H. Utsunomiya, N. Tsuji, and T. Sakai, "Novel ultrahigh straining process for bulk materials development of the accumulative roll-bonding (ARB) process," Acta Materialia, vol. 47, no. 2, pp. 579-583, 1999.

[9] N. Tsuji, Y. Saito, H. Utsunomiya, and S. Tanigawa, "Ultrafine grained bulk steel produced by accumulative roll-bonding
(ARB) process," Scripta Materialia, vol. 40, no. 7, pp. 795-800, 1999.

[10] M. T. Pérez-Prado, J. A. Del Valle, and O. A. Ruano, "Grain refinement of MG-Al-Zn alloys via accumulative roll bonding," Scripta Materialia, vol. 51, no. 11, pp. 1093-1097, 2004.

[11] H. W. Höppel, J. May, and M. Göken, "Enhanced strength and ductility in ultrafine-grained aluminium produced by accumulative roll bonding," Advanced Engineering Materials, vol. 6, no. 9, pp. 781-784, 2004.

[12] K. S. Suresh, S. Sinha, A. Chaudhary, and S. Suwas, "Development of microstructure and texture in Copper during warm accumulative roll bonding," Materials Characterization, vol. 70, pp. 74-82, 2012.

[13] S. H. Lee, Y. Saito, T. Sakai, and H. Utsunomiya, "Microstructures and mechanical properties of 6061 aluminum alloy processed by accumulative roll-bonding," Materials Science and Engineering A, vol. 325, no. 1-2, pp. 228-235, 2002.

[14] N. Tsuji, Y. Ito, Y. Saito, and Y. Minamino, "Strength and ductility of ultrafine grained aluminum and iron produced by ARB and annealing," Scripta Materialia, vol. 47, no. 12, pp. 893899, 2002.

[15] K. Inoue, N. Tsuji, and Y. Saito, "Ultra Grain Refinement of 36\%Ni Steel by Accumulative Roll-Bonding (ARB) Process," in Proceedings of the International Symposium on Ultrafine Grained Steels (ISUGS '01), pp. 126-129, ISI), Fukuoka, Japan, 2001.

[16] N. Tsuji, Y. Saito, H. Utsunomiya, and T. Sakai, "Ultra-fine grained ferrous and aluminum alloys produced by accumulative roll-bonding," in Ultrafine Grained Materials, p. 207, TMS, 2000.

[17] N. Tsuji, Y. Saito, H. Utsunomiya, and T. Sakai, The Proceeding of the Fourth International Conference on Recrystallization and Phenomena, vol. 13, The Japan Institute of Metals, Sendai, Japan, 1999.

[18] X. Huang, N. Tsuji, N. Hansen, and Y. Minamino, "Microstructural evolution during accumulative roll-bonding of commercial purity aluminum," Materials Science and Engineering A, vol. 340, no. 1-2, pp. 265-271, 2003.

[19] Y. Iwahashi, Z. Horita, M. Nemoto, and T. G. Langdon, "The process of grain refinement in equal-channel angular pressing," Acta Materialia, vol. 46, no. 9, pp. 3317-3331, 1998.

[20] K.-T. Park, H.-J. Kwon, W.-J. Kim, and Y.-S. Kim, "Microstructural characteristics and thermal stability of ultrafine grained $6061 \mathrm{Al}$ alloy fabricated by accumulative roll bonding process," Materials Science and Engineering A, vol. 316, no. 1-2, pp. 145152, 2001.

[21] R. Z. Valiev, N. A. Krasilnikov, and N. K. Tsenev, "Plastic deformation of alloys with submicron-grained structure," Materials Science and Engineering A, vol. 137, pp. 35-40, 1991.

[22] M. Furukawa, Z. Horita, M. Nemoto, R. Z. Valiev, and T. G. Langdon, "Microhardness measurements and the hall-petch relationship in an Al-Mg alloy with submicrometer grain size," Acta Materialia, vol. 44, no. 11, pp. 4619-4629, 1996.

[23] Z. P. Xing, S. B. Kang, and H. W. Kim, "Structure and properties of AA3003 alloy produced by accumulative roll bonding process," Journal of Materials Science, vol. 37, no. 4, pp. 717-722, 2002.

[24] K. Nakashima, Z. Horita, M. Nemoto, and T. G. Langdon, "Development of a multi-pass facility for equal-channel angular pressing to high total strains," Materials Science and Engineering $A$, vol. 281 , no. $1-2$, pp. $82-87,2000$. 

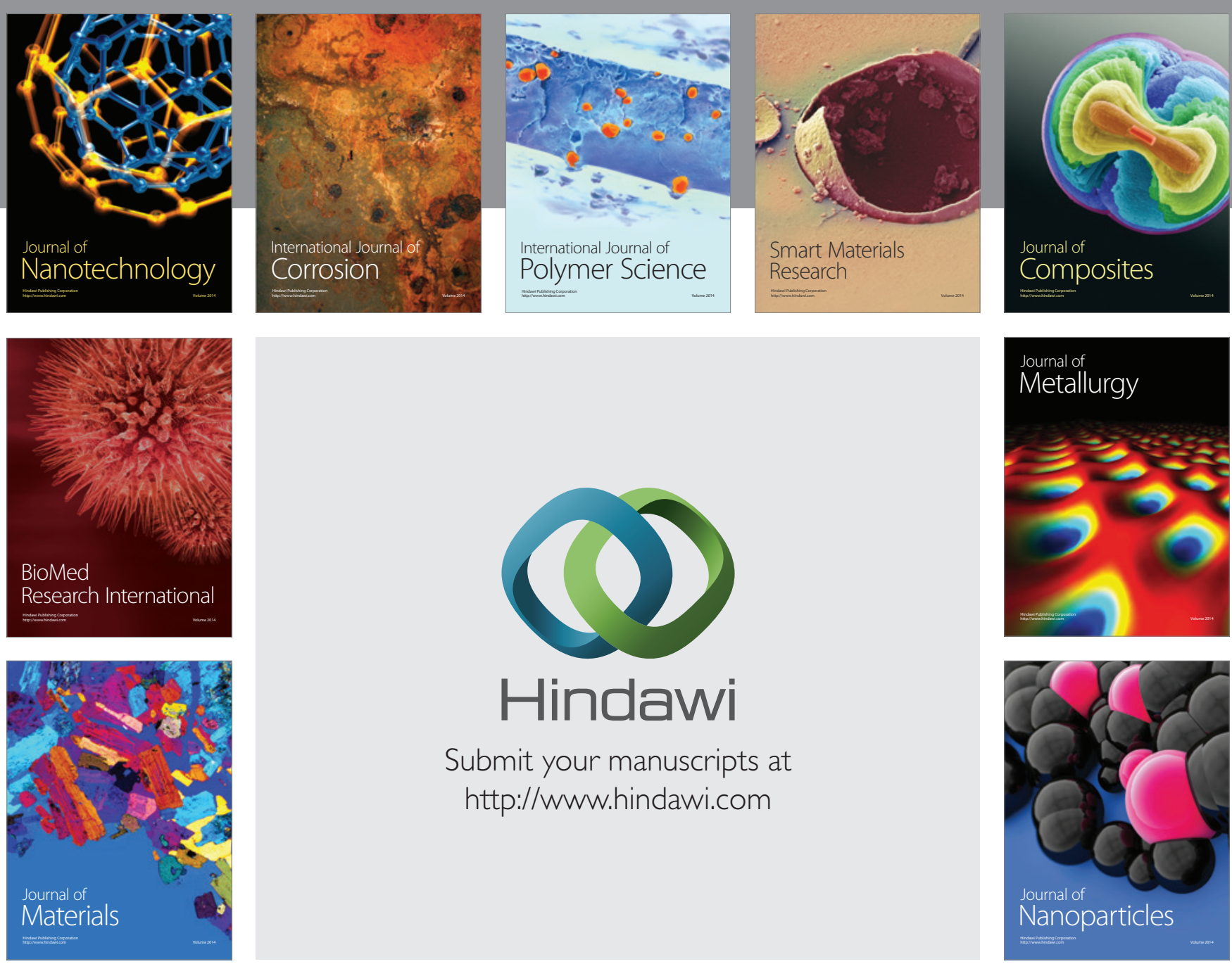

Submit your manuscripts at http://www.hindawi.com
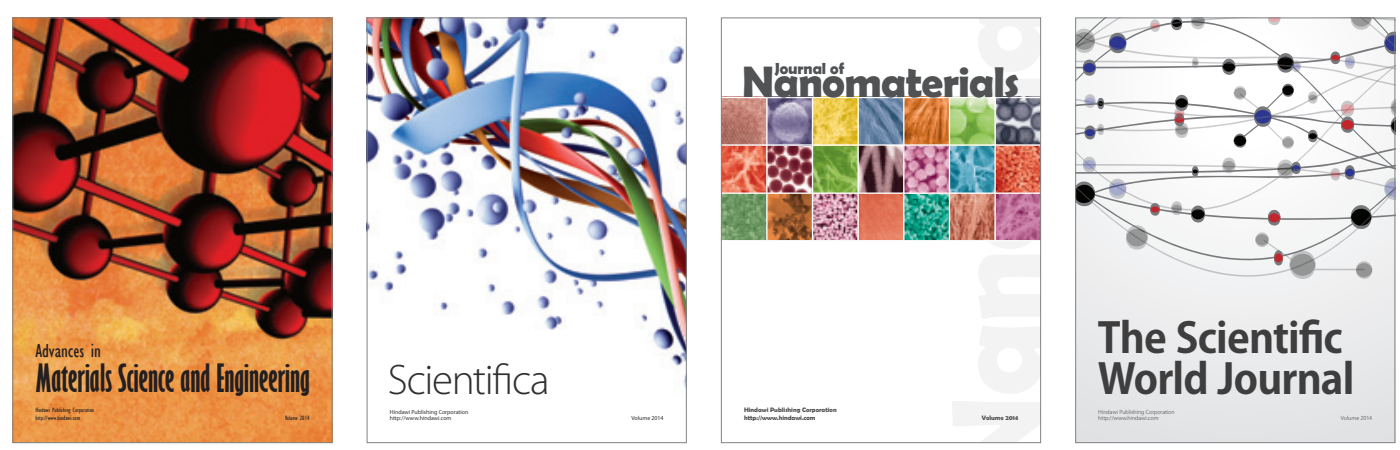

\section{The Scientific World Journal}
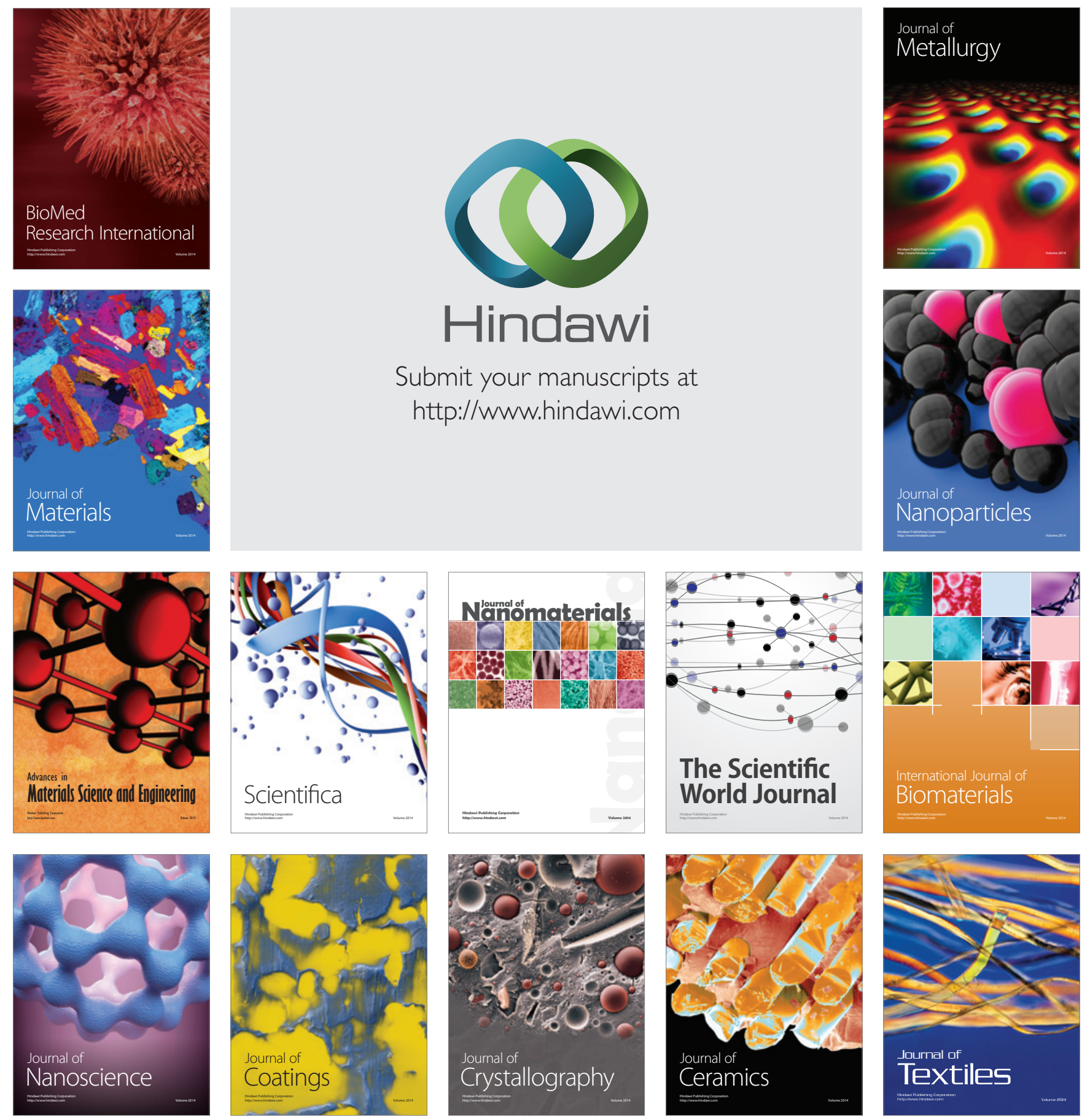